\title{
Malaria transmission after five years of vector control on Bioko Island, Equatorial Guinea
}

Hans J Overgaard ${ }^{1,4^{*}}$, Vamsi P Reddy ${ }^{2}$, Simon Abaga ${ }^{3}$, Abrahan Matias ${ }^{4}$, Michael R Reddy ${ }^{5}$, Vani Kulkarni ${ }^{2}$, Christopher Schwabe ${ }^{4}$, Luis Segura ${ }^{6}$, Immo Kleinschmidt ${ }^{7}$ and Michel A Slotman ${ }^{2}$

\begin{abstract}
Background: Malaria is endemic with year-round transmission on Bioko Island. The Bioko Island Malaria Control Project (BIMCP) started in 2004 with the aim to reduce malaria transmission and to ultimately eliminate malaria. While the project has been successful in reducing overall malaria morbidity and mortality, foci of high malaria transmission still persist on the island. Results from the 2009 entomological collections are reported here.
\end{abstract}

Methods: Human landing collections (HLC) and light trap collections (LTC) were carried out on Bioko Island, Equatorial Guinea in 2009. The HLCs were performed in three locations every second month and LTCs were carried out in 10 locations every second week. Molecular analyses were performed to identify species, detect sporozoites, and identify potential insecticide resistance alleles.

Results: The entomological inoculation rates (EIR) on Bioko Island ranged from 163 to 840, with the outdoor EIRs reaching $>900$ infective mosquito bites per year. All three human landing collection sites on Bioko Island had an annual EIR exceeding the calculated African average of 121 infective bites per year. The highest recorded EIRs were in Punta Europa in northwestern Bioko Island with human biting rates of 92 and 66 mosquito landings per person per night, outdoors and indoors, respectively. Overall, the propensity for mosquito biting on the island was significantly higher outdoors than indoors $(p<0.001)$. Both Anopheles gambiae s.s. and An. melas were responsible for malaria transmission on the island, but with different geographical distribution patterns. Sporozoite rates were the highest in An. gambiae s.s. populations ranging from 3.1\% in Punta Europa and 5.7\% in Riaba in the southeast. Only the L1014F (kdr-west) insecticide resistance mutation was detected on the island with frequencies ranging from 22-88\% in An. gambiae s.s. No insecticide resistance alleles were detected in the An. melas populations.

Conclusions: In spite of five years of extensive malaria control and a generalized reduction in the force of transmission, parasite prevalence and child mortality, foci of very high transmission persist on Bioko Island, particularly in the northwestern Punta Europa area. This area is favorable for anopheline mosquito breeding; human biting rates are high, and the EIRs are among the highest ever recorded. Both vector species collected in the study have a propensity to bite outdoors more frequently than indoors. Despite current vector control efforts mosquito densities remain high in such foci of high malaria transmission. To further reduce transmission, indoor residual spraying (IRS) needs to be supplemented with additional vector control interventions.

Keywords: Entomological inoculation rate, Sporozoite, Human biting, Light traps, Anopheles

\footnotetext{
* Correspondence: hans.overgaard@umb.no

'Department of Mathematical Sciences and Technology, Norwegian

University of Life Sciences, Ås, Norway

${ }^{4}$ Medical Care Development International, Silver Spring, MD, USA

Full list of author information is available at the end of the article
}

\section{() Biomed Central}

(c) 2012 Overgaard et al.; licensee BioMed Central Ltd. This is an Open Access article distributed under the terms of the Creative Commons Attribution License (http://creativecommons.org/licenses/by/2.0), which permits unrestricted use, distribution, and reproduction in any medium, provided the original work is properly cited. 


\section{Background}

The Bioko Island Malaria Control Project (BIMCP) in Equatorial Guinea is a public-private and civil-society partnership between Marathon Oil Corporation and its corporate partners; Medical Care Development International, a private voluntary organization; academic institutions; and the Government of Equatorial Guinea. The first five year phase of the project began in 2004 and was extended by a second five year term starting in 2009. The goal of the project is to substantially reduce malaria transmission and its associated morbidity and mortality and ultimately to potentially eliminate malaria on Bioko Island. The malaria control strategy of the BIMCP is based on a set of integrated interventions combining vector control, effective case management, prevention of malaria during pregnancy, behavioral change communications, monitoring and evaluation, and operational research [1]. The mosquito vector suppression activities include twice-yearly indoor residual spraying (IRS) of insecticides on interior walls of all inhabited dwellings. In 2007 long-lasting insecticide treated bednets (LLIN) were distributed to all households to cover all sleeping areas [2].

Case management consists of improved case detection and access to artemisinin combination therapy to treat diagnosed cases. Pregnant women are provided with intermittent preventive treatment with two doses of sulfadoxine-pyrimethamine(SP), at least 30 days apart and LLINs at antenatal care visits, and confirmed cases are treated with quinine and given iron supplementation. An integrated behavioral change and communication (BCC) and information, education and communication (IEC) component supports project activities. In addition, a comprehensive island-wide monitoring and evaluation program has been established, which includes surveillance of malaria cases, vector monitoring, assessment of transmission intensity, insecticide efficacy and resistance, insecticide and medicine stocks, and support to improve the national health information system.

The results of these concerted efforts reduced malaria prevalence from $42 \%$ to $18 \%$ in children two to five years old and all cause under-five mortality from 155 per 1000 births to 52 per 1000 between 2004 and 2008 [3]. Although there was substantial variation in child malaria between sentinel sites, significant reductions were achieved in most sites [3] with the exception of the northwestern coastal region of Punta Europa, where malaria transmission appeared to be largely unaffected and remained at high levels [3-5].

During 2004-2008, vector monitoring was conducted through a household-based network of window exit traps installed in six houses in each of sixteen sentinel sites. The abundance of An. melas and An. funestus collected in window traps after the first spray round were reduced by $87 \%$ and $85 \%$, respectively, suggesting high susceptibility to pyrethroids. The number of An. funestus collected continued to decline, and only three specimens were found after the third spray round [6]. The abundance of collected Anopheles gambiae s.s. appeared to be less affected by the first spray round with pyrethroids, but did decline by $93 \%$ after introduction of bendiocarb during the second spray round. Despite this apparent lack of impact on Anopheles gambiae densities, the first spray round did have a significant impact on transmission $[1,6]$, probably due to the reduction in An. gambiae sporozoite rates after the spray round, which could have resulted from reduced longevity due to spraying.

Both $\mathrm{M}$ and $\mathrm{S}$ molecular forms of An. gambiae s.s. were identified. The $k d r$ resistance mutation was detected with a high frequency in the $\mathrm{M}$ form at Punta Europa (85\%) [6], but was also present in the $S$ form (Kleinschmidt, unpublished data). Subsequently, the proportion of An. gambiae that belonged to the $\mathrm{S}$ molecular form declined rapidly [6]. The window trap data suggested that the densities of malaria vectors on Bioko Island were reduced to very low levels during the first phase of the project. After the third spray round, only 139 mosquitoes were collected in the window traps, and none of these tested positive for Plasmodium sporozoites [6]. However, this apparently low mosquito abundance did not correspond with data from parasitemia surveys showing high malaria prevalence in certain areas where few mosquitoes were collected.

Though there is evidence in areas with intense transmission, like Bioko, that reductions in parasite prevalence can lag substantially behind reductions in entomological indicators of the effects of vector control [7], this evidence called into question the quality of the vector monitoring system being employed on Bioko Island. In 2008 a review of the performance of window traps revealed that the traps were functioning suboptimally and that light trap collections (LTC) and human landing collections (HLC) collected a much larger number of mosquitoes. This resulted in a decision to fundamentally change the vector monitoring strategy. This new strategy focused on adult mosquito collections through HLC and LTC to monitor vector density, species composition, insecticide resistance allele frequencies and sporozoite rates. In addition, operations research with the aim of answering critical emerging research questions were incorporated in the BIMCP [8-11]. Here we report the results from the vector monitoring conducted in 2009, based on this new strategy and describe vector density, biting times and venue, species composition, sporozoite rates, entomological inoculation rates (EIR), and frequency of insecticide resistance alleles. 


\section{Methods \\ Study area}

Bioko Island belongs to Equatorial Guinea and is located in the Bay of Guinea in Central Africa about $30 \mathrm{~km}$ southwest of the Cameroon coast. The surface area of Bioko Island is $\sim 2,000 \mathrm{~km}^{2}$. Most of the island's 260,000 inhabitants live in the northern part of the island. The discovery of large offshore oil reserves in the 1990's has resulted in rapid economic growth and an overall increase in incomes, although a substantial proportion of the island's residents still practice subsistence agriculture and fishing. The interior of the island is covered with dense forests on the steep slopes of volcanoes and calderas. The highest peak on the island reaches $3,011 \mathrm{~m}$ above sea level. The mean annual rainfall is $\sim 2,000 \mathrm{~mm} /$ year. The rainy season starts in May and ends in October with peaks in August and September of $\sim 300 \mathrm{~mm} /$ month. Mean daily maximum and minimum temperatures range between $29-32^{\circ} \mathrm{C}$ and $19-22^{\circ} \mathrm{C}$, respectively. The island has a humid tropical environment. Malaria is endemic with year-round transmission. A set of 18 sentinel sites were established in 2004 as part of the BIMCP to monitor entomological, clinical and population indicators [1].

\section{Mosquito collections}

Mosquitoes were collected using a combination of HLC conducted every two months and LTC performed approximately every two weeks. The HLC were carried out to determine reliable estimates of the human biting rate. Ethical clearance for the use of HLC was obtained from the National Malaria Control Program of the Ministry of Health and Social Welfare of the Equatoguinean government. HLC were carried out in three sites; Mongola (northwestern Punta Europa region), Arena Blanca (southwestern Luba region), and Riaba (southeastern region); in March, May, July, September, and November 2009 (Figure 1). These sites were selected based on being as representative as possible for the island and still logistically feasible to carry out, but also for the importance of monitoring mosquito populations in areas with a high number of malaria cases, such as in the Punta Europa area. Arena Blanca is a new collection site which was added in 2009 and was not part of the original sentinel sites in which window trap collections were performed. Collections were carried out during two consecutive days in each collection month, except in March in Mongola, when four days of consecutive collections were performed. In each site, four houses were randomly selected from a list of houses used in the annual BIMCP parasitemia survey. Where feasible, the same houses were used throughout the year. In each house, two local volunteers, one positioned indoors and the other outdoors, collected mosquitoes landing on exposed legs and feet from 19:00 to 06:00. Volunteers were informed about the potential risks of collecting mosquitoes, gave informed consent in writing, and were offered treatment if they became ill. The collected mosquito specimens were combined per collection hour. Collectors changed between indoor and outdoor positions at midnight. For each site eight people performed collections per night (4 outdoors and 4 indoors), resulting in a total of 128 indoor and 128 outdoor collection nights during 2009. In addition to these HLCs, indoor LTCs were carried out in the same houses and during the same nights in the same way as described below.

Regular indoor LTCs were carried out to estimate seasonal and spatial variations in indoor mosquito density. These were performed in 10 sites around the island (Figure 1) on an approximately biweekly basis from February to December 2009. These sites were selected based on local malaria transmission (malaria prevalence stratified into five categories derived from annual parasitemia surveys [4] and unpublished data), geographical location, and whether sites were urban or rural (Table 1). Seven sentinel sites coincided with locations from which window trap data are available [6]. Two additional sites (Biabia and Cacahual) were selected in Punta Europa to strengthen monitoring in this area of high malaria prevalence and the tenth site was Arena Blanca. A modified CDC light trap with ultraviolet light emitting diode (UV LED) [12] was installed in an occupied bedroom, about $1.5 \mathrm{~m}$ above the floor, $20-50 \mathrm{~cm}$ from a mosquito net (if present) and/or ca. $50-100 \mathrm{~cm}$ from the nearest window to the bed. Rain shields were removed from traps so as not to obstruct the light source unduly or interfere with the daily life of household inhabitants.

Where possible, traps were placed in the same location within the home for each sampling event. Light traps were operating from 18:00 to 06:00 during one night in five houses per site in the biweekly LTC and during two nights in each of four houses per site in the bimonthly LTC. To summarize, there were seventeen LTC events in all ten sites and an additional five LTC events coinciding with the HLC, totalling 938 LTC trap-nights.

\section{Precipitation}

Rainfall data were collected daily from Mongola during the whole study period using a standard plastic rain gauge.

\section{Specimen handling and molecular analyses}

Adult specimens were brought back to the laboratory where they were sorted, counted, and classified according to genus and blood feeding status (unfed or fed) during each collection event. Specimens, separated by collection method, day, and hour were placed in $70 \%$ 


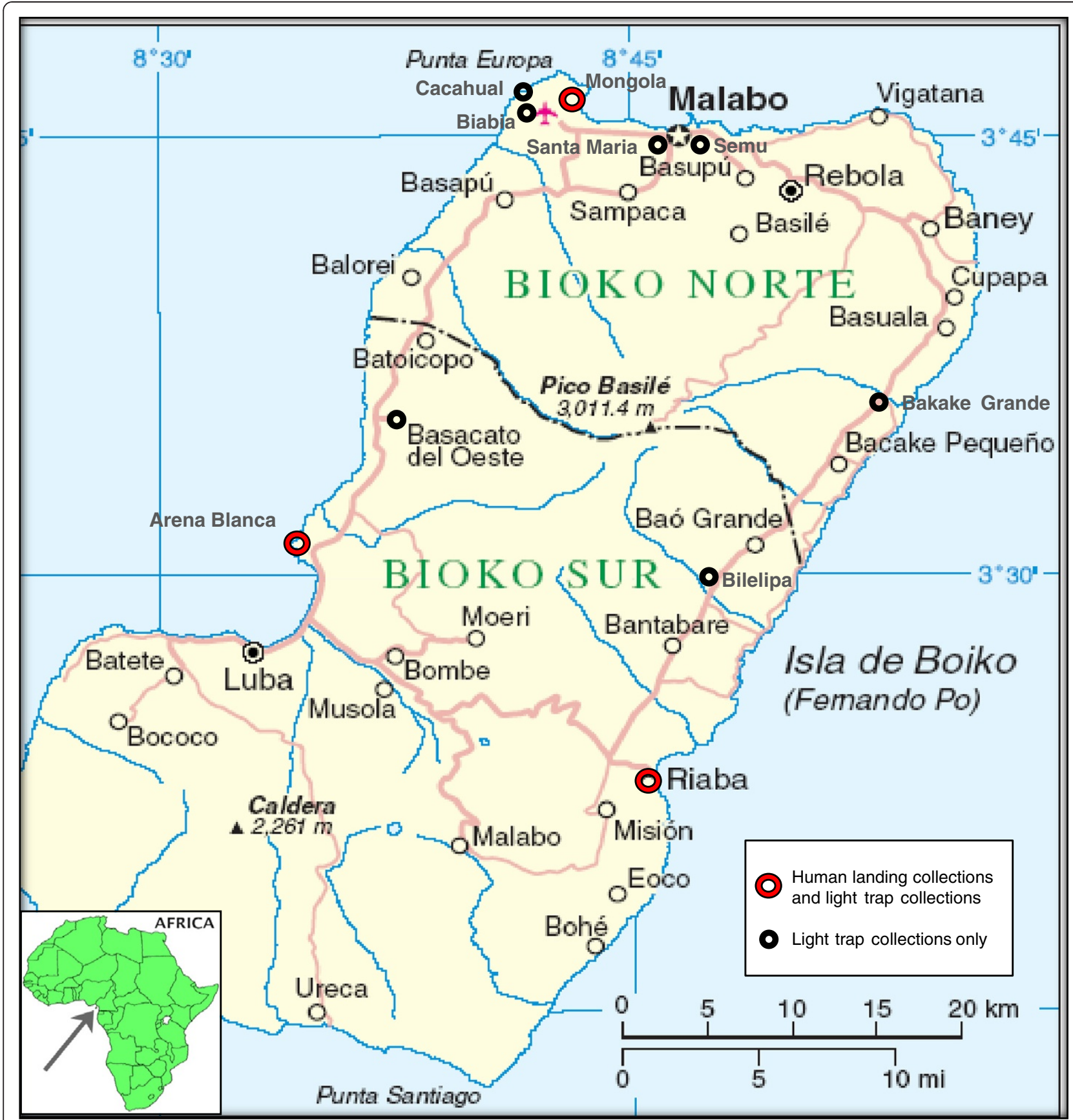

Figure 1 Mosquito collection sites of the Bioko Island Malaria Control Project, Bioko Island, Equatorial Guinea. The three sites in the Punta Europa area together make up the Punta Europa sentinel site. Arena Blanca is not part of the original sentinel sites, but was added as a mosquito collection site in 2009. (Source: Map No. 3861 Rev. 4, January 2005, Department of Peacekeeping Operations Cartographic Section, United Nations. http://www.un.org/Depts/Cartographic/map/profile/eqguinea.pdf.).

alcohol and stored until shipped to Texas A\&M University for molecular analysis. Heads and thoraces of nonbloodfed mosquitoes were dissected and subjected to DNA extraction using a QIAGEN DNeasy Blood \& Tissue Kit on a QIAGEN Biosprint (QIAGEN Sciences Inc.,
Germantown, MD). A diagnostic PCR followed by restriction enzyme digest was used for species identification within the An. gambiae s.l. complex, as well as molecular form [13,14]. Plasmodium falciparum sporozoite detection was performed using the Pf1 and Pf2 primers 
Table 1 Selected sentinel sites of the Bioko Island Malaria Control Project, Equatorial Guinea for vector monitoring

\begin{tabular}{lllll}
\hline Sentinel site & Malaria prevalence (\%) & Geographical location & Setting & Collection method \\
\hline 1. Punta Europa - Mongola & $>50$ & North West & Rural & HLC + LTC \\
2. Punta Europa - Biabia & $>50$ & North West & Rural & LTC \\
3. Punta Europa - Cacahual & $>50$ & North West & Rural & LTC \\
4. Riaba & $30-40$ & South East & Rural & HLC + LTC \\
5. Basacato del Oeste & $30-40$ & South East & Urban & LTC \\
6. Santa Maria & $30-40$ & North & Rural & HLC + LTC \\
7. Arena Blanca & $30-40$ & South West & Rural & LTC \\
8 Bilelipa & $20-30$ & East & Urban & LTC \\
9. Semu & $10-20$ & North & Rural & LTC \\
10. Bakake Grande & $<10$ & East &
\end{tabular}

Selection was based on combined malaria prevalence during 2004-2008 (from Kleinschmidt et al. [4] and unpublished data), geographical location, and setting. $\mathrm{HLC}=$ Human Landing collections. LTC $=$ Light trap collections .

developed by Morassin et al. [15] using slightly modified PCR conditions. Detection of the knock-down resistance alleles L1014F and L1014S (previously referred to as $k d r$-west and $k d r$-east, respectively), as well as the insensitive acetylcholinesterase (iAChE) allele was performed using the real-time Taqman assays developed by Bass et al. [16,17].

\section{Data analyses}

The Wilcoxon signed-rank test was conducted to evaluate whether more mosquitoes were collected outdoors than indoors by HLC. The total number of mosquitoes collected outdoors and indoors for each collection day and location ( $\mathrm{n}=32$ collection events) were used in the analysis. The test was carried out in IBM SPSS Statistics 19. The sporozoite rates between An. melas and An. gambiae s.s. in the LTC in Arena Blanca were compared by the two-proportion Z-test using a web based tool (http://in-silico.net/tools/statistics/ztest/).

\section{Results}

Human landing collections (HLC)

A total of 11,822 Anopheles mosquitoes were collected by HLC in the three locations, of which 3,043 were further analyzed (Table 2). Mongola, one of the villages in the Punta Europa area in the northwest part of the island, had by far the highest human biting rate (HBR) averaging
79.2 mosquitoes per person night, yielding 7,604 (4,432 outdoors vs. 3,172 indoors), which represented $64.3 \%$ of the total number of mosquitoes collected by HLC on Bioko Island in 2009. In Arena Blanca and Riaba, the average HBRs were 36.3 and 16.4 respectively, resulting in 2,905 collected specimens in Arena Blanca (1,635 outdoors vs. 1,270 indoors) and 1,313 mosquitoes in Riaba (816 outdoors vs. 497 indoors). The number of anopheline mosquitoes collected throughout 2009 in the HLC did not show a consistent pattern across the three sites (Figure 2, Figure 3a). For example, in Mongola the number of mosquitoes was high in September, both indoors and outdoors, whereas in Arena Blanca few mosquitoes were collected in this month. In Riaba, relatively little variation in the number of mosquitoes collected was observed throughout the year.

The Wilcoxon test showed that, overall for the island, significantly more Anopheles mosquitoes were collected outdoors than indoors by human landing $(\mathrm{Z}=-3.626, \mathrm{n}=32, \mathrm{p}<0.001)$. Specifically, significantly more mosquitoes bit human subjects seated outdoors than indoors in Mongola $(\mathrm{Z}=-2.59, \mathrm{p}=0.01, \mathrm{n}=12)$ and Riaba $(\mathrm{Z}=-2.701, \mathrm{p}=0.007, \mathrm{n}=10)$, but not in Arena Blanca $(\mathrm{Z}=-1.481, \mathrm{p}=0.139, \mathrm{n}=10)$.

The three sites represent different species composition profiles, with Mongola collections consisting almost exclusively of An. gambiae s.s. (99.6\%). In contrast, the

Table 2 Number of anophelines collected and analyzed for species composition, and average sporozoite rates in human landing collections

\begin{tabular}{|c|c|c|c|c|c|c|c|}
\hline \multirow{3}{*}{$\begin{array}{l}\text { Location } \\
\text { Mongola }\end{array}$} & \multirow{3}{*}{$\begin{array}{l}\text { No. Anopheles collected (no. analyzed) } \\
7,604(1,211)\end{array}$} & \multicolumn{4}{|c|}{ Species composition } & \multicolumn{2}{|c|}{ Pf sporozoite rate $\%( \pm 95 \%$ C.I. $)$} \\
\hline & & \multicolumn{2}{|c|}{ An. gambiae s.s. } & \multicolumn{2}{|c|}{ An. melas } & \multirow{2}{*}{$\begin{array}{l}\text { An. gambiae s.s. } \\
3.1( \pm 1.0)\end{array}$} & \multirow{2}{*}{$\begin{array}{l}\text { An. melas } \\
0\end{array}$} \\
\hline & & 1,207 & $99.6 \%$ & 4 & $0.3 \%$ & & \\
\hline Arena Blanca & $2,905(917)$ & 71 & $7.7 \%$ & 846 & $92.3 \%$ & 0 & $1.2( \pm 0.7)$ \\
\hline Riaba & 1,313 (915) & 423 & $46.2 \%$ & 492 & $53.8 \%$ & $5.7( \pm 2.2)$ & $2.8( \pm 1.5)$ \\
\hline
\end{tabular}

Mosquitoes collected both indoors and outdoors in 2009 in Mongola, Arena Blanca, and Riaba, Bioko Island, Equatorial Guinea. Sporozoite rates averaged over the whole year. $P f=$ Plasmodium falciparum. C.I.=Confidence intervals. 


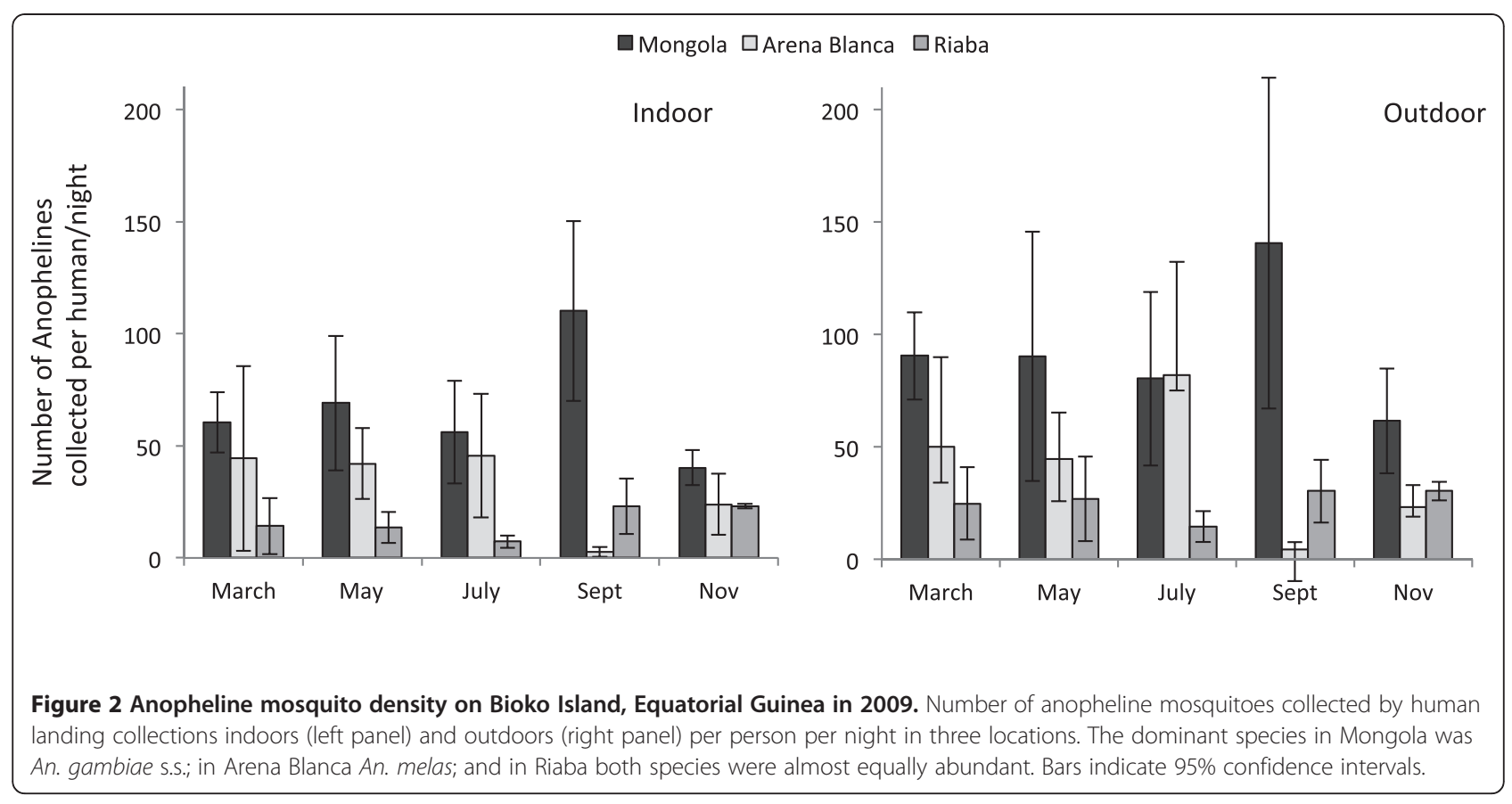

collections from Arena Blanca consisted of 92.3\% An. melas with the remainder being An. gambiae s.s. Both species were almost equally abundant in Riaba, with $46.2 \%$ belonging to An. gambiae s.s. and $53.7 \%$ to $A n$. melas. Every An. gambiae s.s. identified from the HLC belonged to the $\mathrm{M}$ molecular form. For 62 mosquitoes the species diagnostic PCR did not yield a result. At least some of these failures were due to technical error as the An. gambiae s.l. specific Taqman assays to detect $k d r$ and/or ace- $1^{\mathrm{R}}$ worked for 35 of these. However, we cannot rule out the possibility that less than $1 \%$ of collected samples represent other anopheline species that were known to be present on Bioko Island [18].

The HBRs and sporozoite rates varied over the year with different patterns across sites. This produced large variations in EIR across sites and seasons (Figure 3). In Mongola the EIR was high in the beginning of the year and then steadily decreased; a pattern that was also observed in Arena Blanca, although the magnitude was much lower. In Riaba there was a peak in EIR in the middle of the year, caused by the very high sporozoite rates in July. The overall EIR in Mongola was calculated to be 840 infective mosquito bites per year, with outdoor and indoor EIRs being 922 and 652, respectively (Figure 4). In Riaba the overall EIR was $311\left(E_{\text {IIR }}\right.$ outdoor $\left.=344 ; E R_{\text {indoor }}=200\right)$ and in Arena Blanca $163\left(\operatorname{EIR}_{\text {outdoor }}=153\right.$; $\left.\operatorname{EIR}_{\text {indoor }}=123\right)$. Anopheles gambiae s.s. and An. melas contributed 100\% to the respective EIRs in Mongola and Arena Blanca. In Riaba, An. gambiae s.s. and An. melas contributed approximately $60 \%$ and $40 \%$, respectively to the EIR.

\section{Biting times and venue}

In all locations, the majority of the biting took place outdoors throughout the night (Figure 5). The biting rates of An. gambiae s.s. in Mongola presented here have been reported before [8]. Biting activity increased steadily until midnight and was high throughout the rest of the night. In Arena Blanca, Anopheles biting rates, representing mostly An. melas, peaked around midnight, although biting activity continued throughout the night. The hourly mosquito biting rates in Riaba, although lower, showed a similar pattern as in Arena Blanca. In all three locations, a substantial amount of the biting activity occurred before midnight, when many people are active outdoors and not protected by IRS and/or LLINs [8]. In Mongola, the proportion of Anopheles mosquitoes collected before midnight outdoors was $35 \%$ and indoors $30 \%$. The corresponding proportions for Arena Blanca were $40 \%$ outdoors and $47 \%$ indoors; and for Riaba $40 \%$ outdoors and $45 \%$ indoors.

\section{Light trap collections (LTC)}

The light trap collections yielded far fewer mosquitoes than the HLC. A total of 4,083 Anopheles mosquitoes were collected in ten locations during a total of 938 LTC nights. There were large temporal and spatial variations in the number of mosquitoes collected throughout the year (Figure 6). Five sites (Mongola, Arena Blanca, Biabia, Riaba, and Cacahual) together produced $>98 \%$ of all Anopheles mosquitoes collected by LTC on Bioko in 2009 

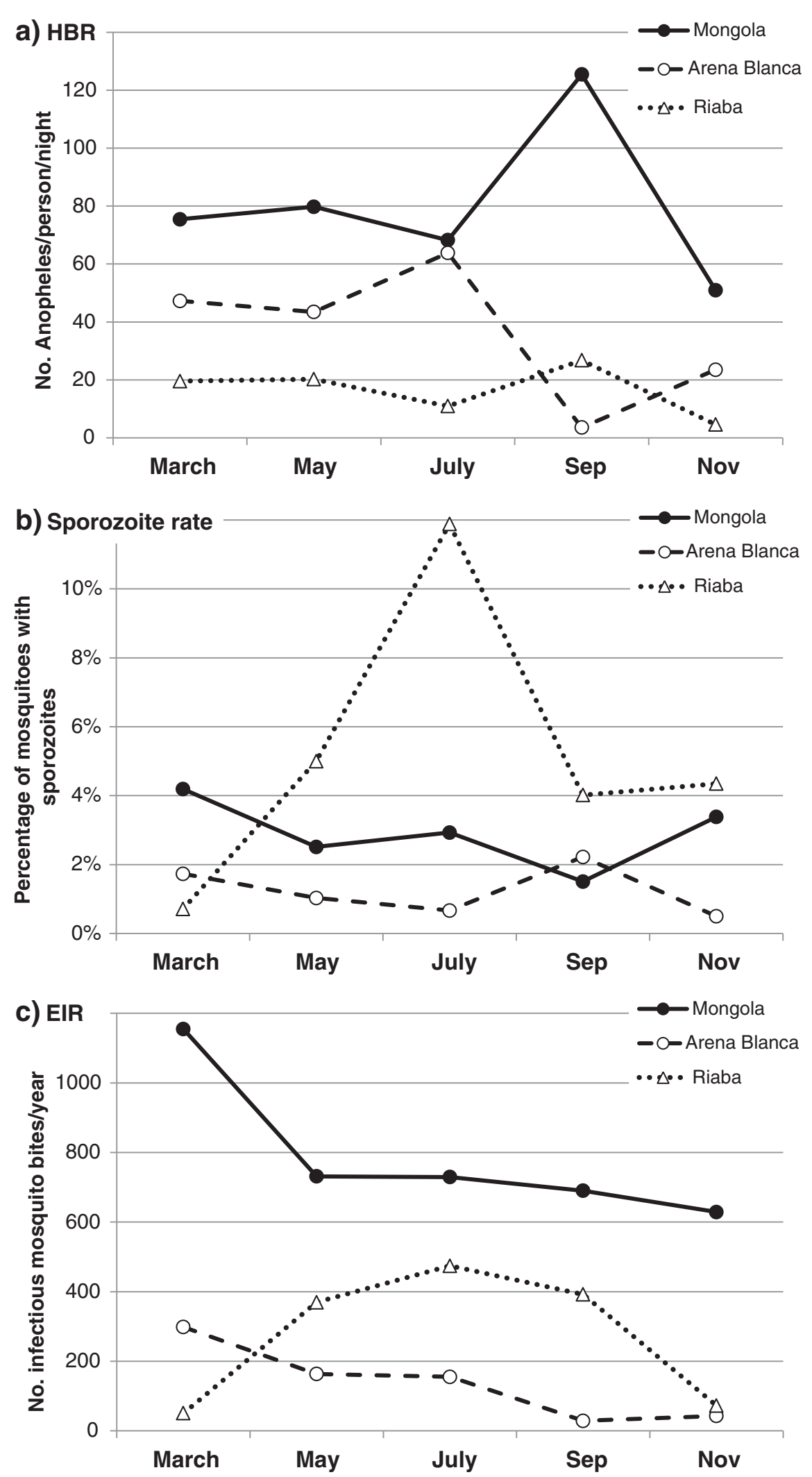

Figure 3 Entomological transmission parameters on Bioko Island, Equatorial Guinea in 2009. Each monthly mosquito collection event was used to calculate a) human biting rates (HBR), b) sporozoite rates, and c) entomological inoculation rates (EIR). 


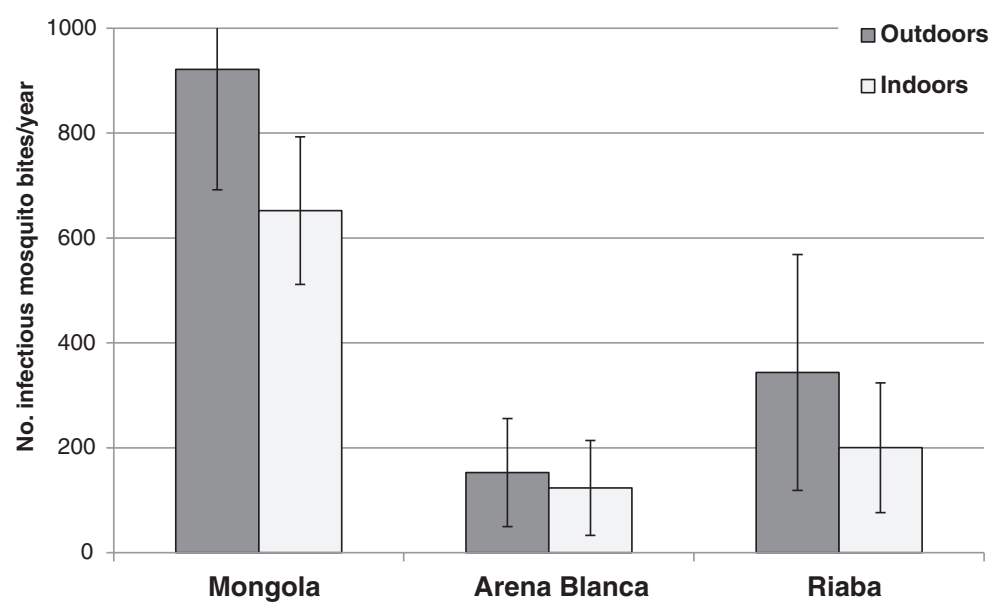

Figure 4 Outdoor and indoor entomological inoculation rates (EIR) in three sites on Bioko Island, Equatorial Guinea in 2009.

Bars indicate $95 \%$ confidence intervals.

(Table 3). The density of Anopheles mosquitoes collected per trap-night was also highest in these same sites.

The three Punta Europa sites (Mongola, Biabia, and Cacahual) comprised $57.5 \%$ of all mosquitoes, with the majority in Mongola (1,754 mosquitoes, $43 \%$ of the total). In Arena Blanca and Riaba light traps collected $1,408(34.5 \%)$ and $285(7.0 \%)$ mosquitoes, respectively. In many locations the light traps collected very few mosquitoes such as in Basacato del Oeste and Bilelipa (Table 3). In six of the ten sites, An. gambiae s.s. was the most common mosquito collected whilst $A n$. melas was the most abundant vector only in Arena Blanca and Riaba (Table 3). All An. gambiae s.s. belonged to the M molecular form.

In the Punta Europa area (Mongola, Biabia, and Cacahual) the number of anopheline captures in light traps peaked during the $1^{\text {st }}$ week of June, whereas in Arena Blanca the main peak occurred during late April. For the Punta Europa sites it seems that reduced mosquito captures generally followed peaks in precipitation, indicating that very high levels of rainfall can reduce the larval productivity.

Sporozoite rates in the LTC could be estimated from only a few locations with any degree of accuracy (Table 3), as the number of collected mosquitoes was low in many locations for both $A n$. gambiae s.s. and $A n$. melas, i.e. most of the confidence interval estimates included 0\%. The sporozoite rates for An. gambiae s.s. were $1.4 \%( \pm 1.3)$ in Mongola and $8.1 \%( \pm 6.8)$ in Cacahual. The overall sporozoite rate for all the $A n$. gambiae s.s. LTC captures was $1.8 \%( \pm 0.9)$. The sporozoite rate in An. melas from the LTC in Arena Blanca was estimated at $1.0 \%( \pm 0.9)$, which was not significantly different from that in An. gambiae in LTC in this location $(\mathrm{z}=0.6251, \mathrm{p}=0.56)$.

\section{Insecticide resistance}

Both An. gambiae and An. melas populations were screened for the presence of three insecticide resistance alleles; L1014F ( $k d r$-west) and L1014S ( $k d r$-east), which provide resistance to DDT and pyrethroids and $a c e-1^{R}$, which provides resistance against carbamates. The only insecticide mutation found was the L1014F and it was only present in $A n$. gambiae s.s. The frequency of this allele was quite heterogeneous across the island ranging from $22.2 \%$ to $87.5 \%$, averaging $48.3 \%$ across eight populations in the LTC. The highest frequencies observed in the urban areas of Semu and Santa Maria (Table 3). The L1014F frequencies obtained in the HLC ranged from $16.9 \%$ to $51.3 \%$ (Table 4 ). No resistance alleles were detected in the $A n$. melas populations.

\section{Precipitation}

The rainy season in 2009 started in March and ended in November (Figure 6). The total amount of rainfall was $1920 \mathrm{~mm}$ with the two major peaks in June $(510 \mathrm{~mm})$ and August $(335 \mathrm{~mm}$ ). More than half of the yearly rainfall occurred in June-August. These months also had more than $60 \%$ rainy days per month. A single tropical storm on 22 June produced $178 \mathrm{~mm}$ in one day.

\section{Discussion}

The results presented here show that, after five years of malaria vector control interventions, and in spite of reductions in the prevalence of human malaria on Bioko Island $[1,3]$, foci of persistent intensive malaria transmission 

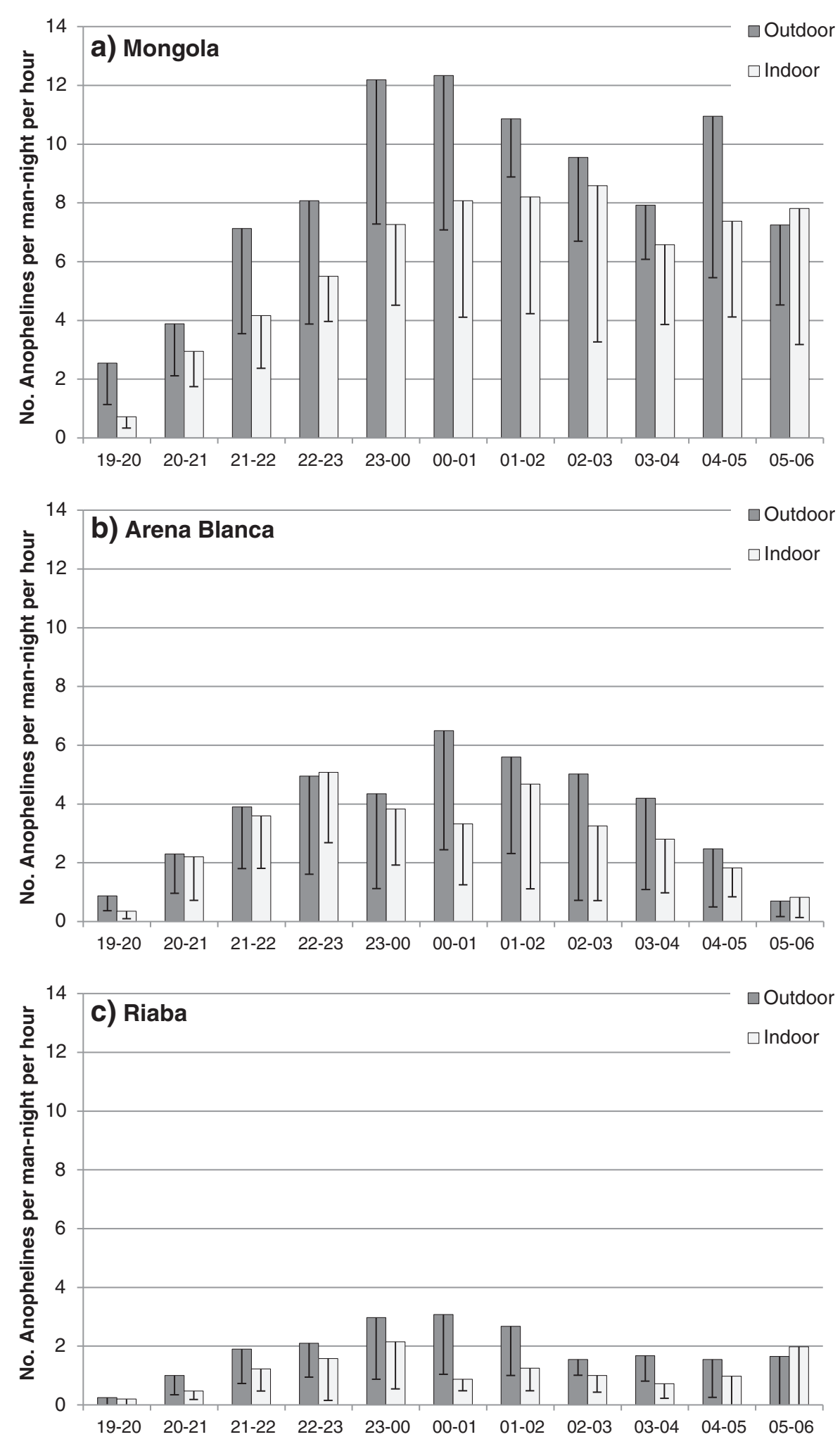

Figure 5 Human landing collections per hour on Bioko Island, Equatorial Guinea. Anopheline mosquitoes collected outdoors and indoors by human landing collections in a) Mongola, b) Arena Blanca, and c) Riaba, Bioko Island, 2009. Bars indicate 95\% confidence intervals. 


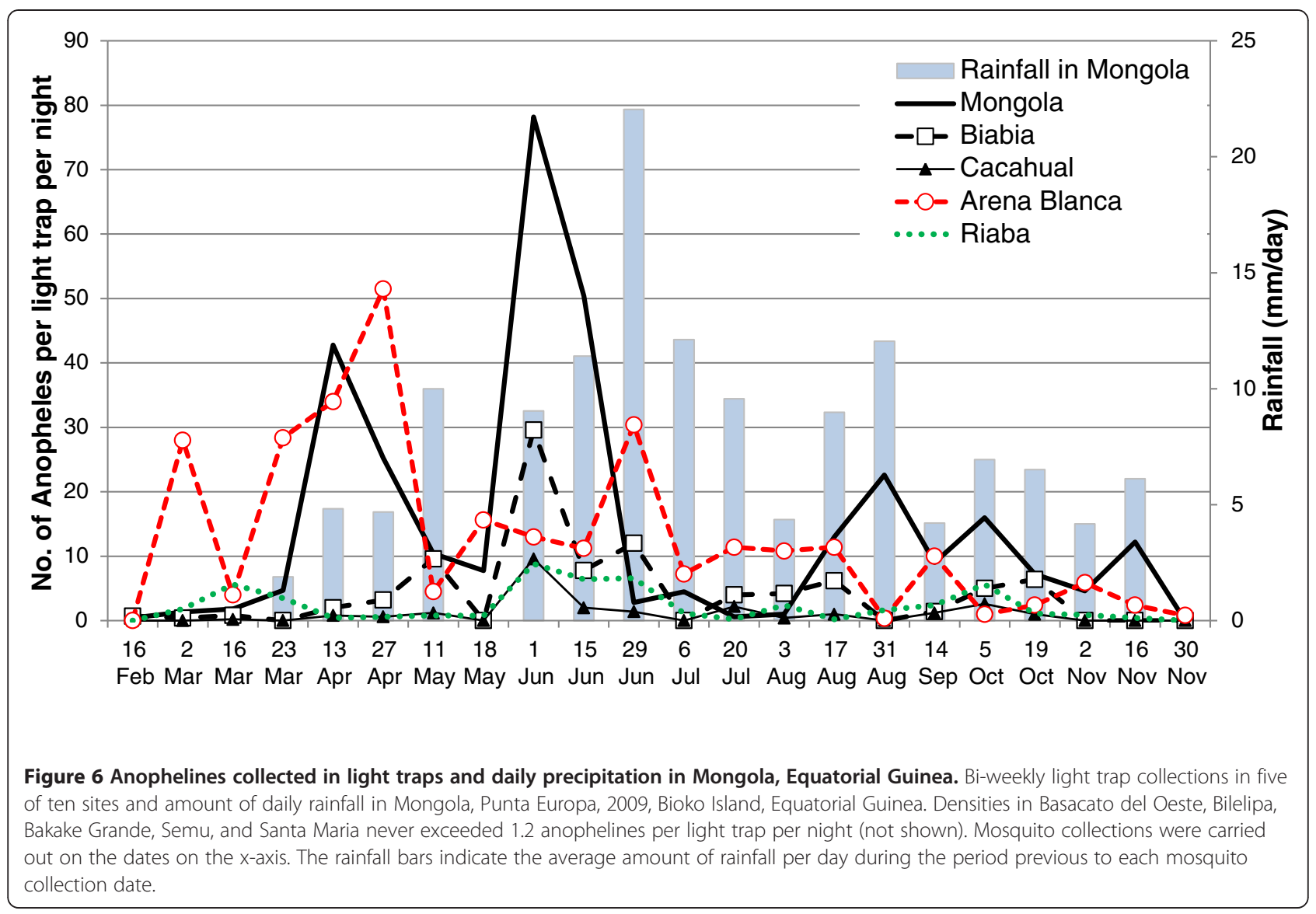

remained. High human biting and sporozoite rates in Punta Europa, in the north-western part of the island, indicate that the human population in this area are potentially exposed to about 840 infective mosquito bites per year when indoor and outdoor biting is taken into account. The outdoor annual EIR was 922 infective mosquito bites per year; using the data from the March collections only the EIR was close to 1200 . These rates are among the highest entomological inoculation rates published in the literature [19-21]. An annual EIR of 1,235 infective bites per person was reported in the early 1990's in Sierra Leone [22], although this value was later revised to 884 by Hay et al. [19]. All three sites where HLC were conducted in the present study had an annual EIR exceeding the calculated African average of 121 infective bites per year [19]. An EIR of 1,030 was reported from Riaba on Bioko Island in the late 1990s [23], suggesting that Bioko Island had one of the (if not the) highest rates of malaria transmission when the control efforts started, and in spite of the intensive and extensive nature of these control efforts, transmission still persists, indicating the need for sustained and scaled up control. This underscores how important it is to have a long-term control framework in place, one that can sustain control over more than the typical project cycle, and one that can adapt to changing transmission realities.

The high EIR in Punta Europa in 2009 resulted from both extremely high HBR and high sporozoite rates. In a review by Hay et al. [19] similar or higher HBRs than this were recorded only from Burundi [24] and Cameroon [25]. More recently, rainy season HBRs in Dakar, Senegal were recorded to be almost three times higher than those reported in the current study [26]. The Punta Europa area is unique for Bioko Island in that it is a fast-growing industrial and commercial zone, where the country's international airport is located. The area is unusually flat compared to the rest of Bioko Island; it has a low forest cover, relatively poor drainage, and consists of many construction sites, all of which contribute to providing excellent mosquito breeding habitats.

Mosquito density in the Punta Europa area has a complex relationship with the daily amount and intensity of rainfall. For example, the 2009 LTCs showed that the high mosquito density in early June followed high rainfall in early May, supplemented by moderate rainfall in the second half of May (Figure 6). On the other hand, the sharp decline in mosquitoes on June 29 was likely due to one single heavy storm downpour on June 22 
Table 3 Entomological data from light trap collections in 2009 on Bioko Island, Equatorial Guinea

\begin{tabular}{|c|c|c|c|c|c|c|c|c|c|c|}
\hline \multirow[b]{2}{*}{ Site } & \multirow[b]{2}{*}{$\begin{array}{l}\text { No. } \\
\text { collected } \\
(\%)\end{array}$} & \multirow[b]{2}{*}{$\begin{array}{l}\text { No. } \\
\text { collection } \\
\text { events }\end{array}$} & \multirow[b]{2}{*}{$\begin{array}{l}\text { Total } \\
\text { no. trap } \\
\text { nights/site }\end{array}$} & \multirow[b]{2}{*}{ Density } & \multicolumn{3}{|c|}{ An. gambiae s.s. } & \multicolumn{3}{|c|}{ An. melas } \\
\hline & & & & & Proportion & L1014F & $\begin{array}{l}P f \\
\text { Sporozoite } \\
\text { rate }\end{array}$ & Proportion & L1014F & $\begin{array}{l}\text { Pf } \\
\text { Sporozoite } \\
\text { rate }\end{array}$ \\
\hline Mongola & $1754(43.0)$ & 22 & 134 & $14.4( \pm 8.2)$ & $99.7( \pm 0.6)$ & $50.6( \pm 3.7)$ & $1.4( \pm 1.3)$ & $0.3( \pm 0.6)$ & 0 & 0 \\
\hline Biabia & $470(11.5)$ & 17 & 90 & $5.5( \pm 3.4)$ & $99.0( \pm 1.1)$ & $43.2( \pm 4.0)$ & $0.7( \pm 0.9)$ & $1.0( \pm 1.1)$ & 0 & $33.3( \pm 53.3)$ \\
\hline Cacahual & $121(3.0)$ & 17 & 89 & $1.4( \pm 1.1)$ & $87.3( \pm 7.7)$ & $30.8( \pm 7.9)$ & $8.1( \pm 6.8)$ & $12.7( \pm 7.7)$ & 0 & 0 \\
\hline Basacato del Oeste & $0(0.0)$ & 14 & 64 & 0 & - & - & - & - & - & - \\
\hline Arena Blanca & $1408(34.5)$ & 21 & 111 & $13.5( \pm 8.2)$ & $11.4( \pm 2.6)$ & $43.1( \pm 8.5)$ & $1.5( \pm 3.0)$ & $88.6( \pm 2.6)$ & 0 & $1.0( \pm 0.9)$ \\
\hline Riaba & $285(7.0)$ & 21 & 125 & $2.4( \pm 1.1)$ & $18.6( \pm 8.4)$ & $22.2( \pm 13.6)$ & 0 & $81.4( \pm 8.4)$ & 0 & $4.3( \pm 4.7)$ \\
\hline Bilelipa & $1(0.02)$ & 16 & 85 & $0.01( \pm 0.02)$ & 0 & 0 & 0 & 100 & 0 & 0 \\
\hline Bakake Grande & $9(0.2)$ & 15 & 80 & $0.1( \pm 0.2)$ & 100 & $42.9( \pm 25.9)$ & 0 & 0 & 0 & 0 \\
\hline Semu & $24(0.6)$ & 16 & 80 & $0.3( \pm 0.2)$ & 100 & $87.5( \pm 11.5)$ & $6.3( \pm 11.9)$ & 0 & 0 & 0 \\
\hline Santa Maria & $11(0.3)$ & 16 & 80 & $0.1( \pm 0.1)$ & 100 & $66.7( \pm 26.7)$ & $16.7( \pm 29.8)$ & 0 & 0 & 0 \\
\hline TOTAL / Average & $4083(100.0)$ & 175 & 938 & $4.7( \pm 1.6)$ & $58.0( \pm 2.6)$ & $46.0( \pm 3.4)$ & $1.8( \pm 0.9)$ & $62.0( \pm 2.6)$ & 0 & $1.7( \pm 0.6)$ \\
\hline
\end{tabular}

Total number, density per light-trap night, proportion of An. gambiae s.s. and An. melas collected in 10 sites, frequency of knockdown resistance mutation L1014F (kdr-west) (\%), and Plasmodium falciparum (Pf) sporozoite rates (\%) found in each species (95\% confidence intervals in parentheses).

(included in the June 29 precipitation bar in Figure 6), which presumably flushed larvae out of their breeding habitats. The mosquito densities in Arena Blanca and Riaba were not affected by precipitation in Punta Europa, probably because of a different rainfall pattern in those locations. It could also be due to the higher number of An. melas collected in these locations. Anopheles melas might be affected differently than $A n$. gambiae s.s. by rainfall patterns, although this was not studied here.

The An. gambiae s.s. populations in Punta Europa also have a relatively high sporozoite rate averaging $\sim 3 \%$ and ranging between $1.0 \%( \pm 1.7 \% 95 \% \mathrm{CI})$ and $3.9 \%( \pm 1.9 \%$ $95 \% \mathrm{CI}$ ) over the year (data by month not shown). In Riaba the sporozoite rate in this species was much higher, at least in the HLC, but a much lower human biting rate resulted in a considerably lower EIR in this location.

Malaria parasites in Punta Europa are highly prevalent in the human population [4,5]. Although the high EIR values reported here indicate a high potential for transmission, this is only realized if the human population is not protected by effective control measures. We have previously reported high outdoor biting rates in this area [8], and given the high effective coverage with IRS and LLINs, a large fraction of the transmission between humans and mosquitoes probably occurs at outdoor venues, including bars and restaurants. Based on the data presented here outdoor biting seems to be prevalent throughout the island. The potential for malaria transmission is further aggravated by the observation that host seeking begins early in the evening. In the current HLCs, about $30-50 \%$ of indoor biting occurred before midnight when the protection from vector control measures is not optimal. About $35-40 \%$ of outdoor biting during HLC occurred before midnight, at a time when most people are active outside their houses and thus being greatly exposed to malaria mosquito bites. The potential for transmission in outdoor venues where people are not protected by IRS and LLIN is therefore considerable and underscores the need for the development of control methods that effectively target outdoor feeding populations in addition to IRS and LLINs.

A recent study from Bioko concluded that there is currently no epidemiological evidence of outdoor biting having an impact on malaria prevalence in children in Bioko [27]. Although the study found that spending time outdoors at night was rare amongst children under 15 years, those who did spend the previous night outdoors did not have a higher prevalence of infection than those who stayed indoors [27]. However, the power of that study to detect an impact of spending time outdoors was limited by the fact that few children slept under a bed net, and that the last IRS spray round was conducted 3-5 months prior to the survey, providing little protective effect to being indoors. Furthermore, adults are far more likely to stay outdoors at night than children and thereby potentially keeping parasites

Table 4 Insecticide resistance in An. gambiae s.s. (M form) captured by HLC on Bioko Island, Equatorial Guinea

\begin{tabular}{lllllll}
\hline & & \multicolumn{5}{c}{$\boldsymbol{k d r}$ genotypes } \\
Location & L1014F frequency & $\mathbf{n}$ & S/S & S/R & R/R & HWD \\
\hline Mongola & $51.3 \%( \pm 2.0)$ & 1195 & 297 & 570 & 328 & $\mathrm{p}=0.29$ \\
Arena Blanca & $39.0 \%( \pm 5.8)$ & 136 & 48 & 70 & 18 & $\mathrm{p}=0.64$ \\
Riaba & $16.9 \%( \pm 2.5)$ & 423 & 300 & 103 & 20 & $\mathrm{p}=0.024$ \\
\hline
\end{tabular}

$\mathrm{S}=\mathrm{L} 1014 \mathrm{~L}$, the susceptible allele. $\mathrm{R}=\mathrm{L} 1014 \mathrm{~F}$, the resistant allele. Frequency of $\mathrm{L} 1014 \mathrm{~F}$ resistance mutation ( $k d r$-west); numbers of mosquitoes tested $(n)$ and identified with susceptible and resistant alleles; and $p$-values for chi-square test of Hardy Weinberg disequilibrium (HWD) from mosquito samples collected by human landing in 2009 in three locations. 
circulating in the general population. Further research is, therefore, required to determine the epidemiological impact of being outdoors in the evening and at night in both children and adults.

In 1998-1999, well before the implementation of the current control program, an annual EIR of 1,030 was reported for Riaba [23]. Anopheles funestus was the main contributor (76\%) to this EIR, whereas An. gambiae was responsible for the remaining $24 \%$. It is quite clear that the entomological situation has changed drastically in Riaba in the thirteen years since the first report. The present results indicate that An. funestus was absent or, at most, occurring at extremely low densities in Bioko, including Riaba. Presumably, the continuous BIMCP vector control activities, particularly IRS, have nearly eliminated An. funestus on Bioko; something which was also observed following the first IRS rounds [6]. Sporozoite rates are still high in Riaba among An. gambiae s.s. and $A n$. melas, indicating that parasite transmission from human to mosquito is high in the area, despite relatively low biting rates compared to the rest of the island. The extreme peak in sporozoite rates in July and low HBRs could be explained by a shift in the age structure of the mosquito populations in this site. For example, if for some reason larval mortality was high for a period, this would result in fewer adult mosquitoes being collected, but they would be older and thus have a higher sporozoite rate.

Somewhat puzzling, Cano et al. [23] conducted malaria mosquito collections in 1998-99 on Bioko Island but did not identify any An. melas specimens, although this species was found at considerable frequency in the current collections in both Riaba and Arena Blanca. Anopheles melas was also present in Riaba in the 2003-2004 pre-spray BIMCP collections with very high sporozoite rates [3]. Possibly, most of the collection sites of Cano et al. [23] were located further inland, away from the coast where An. melas breeding sites are located.

In Arena Blanca, An. melas was the major malaria vector. This site is close to the town of Luba, but the environmental and socioeconomic conditions differ markedly from Luba. Arena Blanca is a small fishing village comprised of approximately 50 houses located directly on the beach. The majority of people living there are Annobonese fishermen with a culture distinctly different from the rest of the island. Arena Blanca is also a popular weekend beach resort for people from around the island. Although the calculated EIR is the lowest on the island, people, including weekenders, are still exposed to an average of about 22 outdoor biting malaria mosquitoes during the first half of the night, of which $\sim 1 \%$ might be infected.

Our results indicate that the $\mathrm{S}$ form of An. gambiae s.s. was eliminated from the island while the $\mathrm{M}$ form remains.
Prior to the BIMCP, $36 \%$ of the An. gambiae s.s. mosquitoes collected on Bioko consisted of the $\mathrm{M}$ form, but by the end of the third spray round this had increased to $80 \%$ [6]. Successive analyses showed that the M-form increased steadily from $80 \%$ in 2005 ( $\mathrm{n}=189), 98 \%$ in 2006 ( $\mathrm{n}=$ 467), $94 \%$ in $2007(\mathrm{n}=79)$, and $100 \%$ in $2008(\mathrm{n}=149)$ (BIMCP unpublished data). In the 2009 collections, none of the 3,043 mosquitoes analyzed (consisting of a proportional sample across all sites and time points) belonged to the $\mathrm{S}$ form of An. gambiae s.s. A possible explanation for the apparent disappearance of the $\mathrm{S}$ form could be differences in the frequencies of $k d r$ mutation between the two molecular forms. Knockdown resistance allele frequencies among An. gambiae on Bioko Island are unusual in that the L1014F allele was at high frequency in the M form, rather than the $\mathrm{S}$ form early on [28]. This contrasts with the situation on the West African mainland, where this allele first spread through $S$ form populations, prior to introgression into the M form [29]. This could potentially have led to the persistence of the $\mathrm{M}$ form and the disappearance of the $\mathrm{S}$ form on Bioko.

On the other hand, a recent modeling study [Kiszewski et al. in review] indicated that $k d r$ alleles limit the efficacy of IRS only to a certain degree making it hard to see how this difference in $k d r$ frequency resulted in the disappearance of the $\mathrm{S}$ form. Likewise, this does not explain the continued decline of the $S$ form after the BIMCP switched to using carbamates in IRS instead of pyrethroids. In the equatorial rain forest of Central Africa, the $\mathrm{M}$ and $\mathrm{S}$ forms are widely sympatric and no niche differentiation has been detected [30]. Another possibility could be that the $\mathrm{M}$ and $\mathrm{S}$ forms differed in their propensity to feed and/or rest indoors, making the $M$ form less susceptible to IRS and LLINs, although an earlier rather limited survey found no evidence of outdoor feeding An. gambiae s.l. on Bioko Island [18]. In addition, or alternatively, the $\mathrm{M}$ form may have been less susceptible to the two classes of insecticides used in the IRS and LLIN campaign due to $k d r$ and more efficient detoxification.

The L1014F mutation was the only insecticide resistance allele detected among the An. gambiae mosquitoes on Bioko. The frequency of L1014F allele varied but exceeded $40 \%$ in most locations. The highest frequency was observed in the urban populated areas in the north of the island; reaching nearly $90 \%$ in Semu. This suggests that insecticide use from previous and present pyrethroid-based control campaigns, but most likely household insecticide use as well, has resulted in increased frequency of the L1014F allele. Large businesses and companies often have their own mosquito control programs independent from the BIMCP, further reinforcing selection pressure for insecticide resistance. Agricultural use of insecticides is not common 
in Equatorial Guinea [31,32] and is therefore unlikely to impact $k d r$ allele frequencies.

Following an initial spray round with a pyrethroid, the BIMCP switched to bendiocarb, a carbamate insecticide, in the IRS. This decision was based on the presence of $k d r$ and absence of ace- $1^{R}$ mutations. As the frequency of $k d r$ mutation was low in An. gambiae s.s. in Riaba and the mutation was absent in An. melas in Arena Blanca, these locations are favorable for a change in insecticide used in IRS. The NMCP of Equatorial Guinea has recently adopted the WHO Guidelines for Insecticide Resistance Management (GPIRM) [33] and decided to switch to pyrethroids on a rotational basis for the whole of Bioko Island.

Although four years of control on Bioko was successful in greatly reducing child mortality [3] and having a dramatic impact on the effective population size of $A n$. gambiae and An. melas [34] entomological indicators indicate that, even if the force of transmission has been substantially reduced relative to pre-intervention levels, it still remains high on the island relative to other African contexts, and that there remain foci of very high transmission. As the current twice-a-year spray rounds with bendiocarb have insufficient residual duration to provide effective control on Bioko [27], the IRS intervention needs to be supported by much higher LLIN coverage and supplemented with an additional set of focally administered control measures [5]. The BIMCP is currently piloting such a stratified focal approach in Punta Europa, combining IRS with universal LLIN distribution, Focal Mass Screening and Treatment (FMST), reinforced IEC/BCC and source reduction through larval source management. Future focal efforts might also evaluate the efficacy of infrastructural modifications and environmental management, along with testing and possible introduction of other transmission barriers (e.g. insecticide treated materials) and personal protection methods. Collaboration between BIMCP, the airport administration, and local businesses is also a strategy that should be explored to reduce mosquito breeding in these areas through infrastructural modification and environmental management. Although the precise impact of outdoor biting on malaria prevalence still needs to be fully clarified, the fact that extensive outdoor biting is occurring on Bioko Island [8] and other parts of Africa [35] suggests that alternative and innovative control options should be developed and implemented to address this problem.

\section{Conclusions}

Results from this study show that in spite of the concerted vector control efforts of the National Malaria Control Program with support from the Bioko Island Malaria Control Project (BIMCP) since 2004, and in spite of the general reduction in the force of transmission, parasite prevalence and mortality on the island, a number of persistent foci of high transmission remain on the island. Principal among these is the Punta Europa area in northwestern Bioko Island, where the entomological inoculation rates remain among the highest ever recorded. People in this area are still exposed to more than 800 infective mosquito bites per year with potentially higher outdoor rates. The area seems to be favorable for malaria mosquito breeding, possibly due to the flat and open areas around the international airport. The number of Anopheles mosquitoes landing on humans and attempting to feed is also among the highest recorded. The twice yearly indoor residual sprays of the BIMCP have not been sufficient to control the density of infected mosquitoes biting people in this area. The recent efforts in Punta Europa to supplement IRS with full coverage of LLINs, Focal Mass Screening and Treatment (FMST), reinforced IEC/BCC and community-based larval source management on a focal basis is an appropriate response to the prevailing transmission characteristics. Depending on the outcome of this pilot initiative, consideration should also be given to coordinated infrastructural modification and environmental management with the airport authorities and local industries. These added efforts might help to further reduce mosquito breeding and potentially also outdoor biting. In addition, the BIMCP may also want to contemplate the introduction of other transmission barriers and personal protection methods in the future. As Bioko Island, like more and more malarious countries, aims for malaria elimination, control strategies will likely need to be stratified to reflect heterogeneous localized transmission characteristics. Elimination of malaria in this setting may require the introduction of focal strategies to successfully address transmission hot spots, including those attributable to outdoor biting.

\section{Competing interests}

The authors declare that they have no competing interests.

\section{Authors' contributions}

HJO: Conceived, supervised, and planned the study, supervised and performed field collections. Wrote the first draft manuscript. VPR: Performed molecular analyses. SA: Participated in the study design, supervised and participated in field collections, and provided editorial input. AM: Participated in field collections. Provided editorial input. MRR: Participated in study design and provided editorial input. VK: Performed molecular analyses. CS: Participated in study design and provided editorial input. LS: Participated in study design and provided editorial input. IK: Participated in study design and provided editorial input. MAS: Participated in study design, supervised the molecular analysis, and contributed to manuscript preparation. All authors read and approved the final version of the manuscript.

\section{Acknowledgements}

The authors gratefully acknowledge Arcadio Edu, Valeriano Oluy, Emilio Bibian, Leonardo Bobuakasi, Jesus Nazareth, and village volunteers for their contributions in the field and laboratory. We are also grateful to Dr. Gloria Nseng, Director of the National Malaria Control Program in Equatorial 
Guinea, and Ed Aldrich from Medical Care Development International (MCDI) for logistical support. This study was supported by the Bioko Island Malaria Control Project which is funded by a consortium led by Marathon Oil Corporation and the Government of Equatorial Guinea.

\section{Author details}

${ }^{1}$ Department of Mathematical Sciences and Technology, Norwegian University of Life Sciences, Ås, Norway. ${ }^{2}$ Department of Entomology, Texas A\&M University, College Station, TX, USA. ${ }^{3}$ National Malaria Control Program, Ministry of Health, Malabo, Equatorial Guinea. ${ }^{4}$ Medical Care Development International, Silver Spring, MD, USA. ${ }^{5}$ Department of Epidemiology and Public Health, Yale University, New Haven, CT, USA. ${ }^{6}$ Swiss Tropical and Public Health Institute, Basel, Switzerland. ${ }^{7}$ MRC Tropical Epidemiology Group, Department of Infectious Disease Epidemiology, London School of Hygiene and Tropical Medicine, London, UK.

Received: 6 October 2012 Accepted: 3 November 2012 Published: 12 November 2012

\section{References}

1. Kleinschmidt I, Sharp B, Benavente LE, Schwabe C, Torrez M, Kuklinski J, Morris N, Raman J, Carter J: Reduction in infection with Plasmodium falciparum one year after the introduction of malaria control interventions on Bioko Island, Equatorial Guinea. Am J Trop Med Hyg 2006, 74:972-978

2. Kleinschmidt I, Schwabe C, Shiva M, Segura JL, Sima V, Mabunda SJ, Coleman M: Combining indoor residual spraying and insecticide-treated net interventions. Am J Trop Med Hyg 2009, 81:519-524.

3. Kleinschmidt I, Schwabe C, Benavente L, Torrez M, Ridl FC, Segura JL, Ehmer P, Nchama GN: Marked Increase in Child Survival after Four Years of Intensive Malaria Control. Am J Trop Medicine Hyg 2009, 80:882-888.

4. Kleinschmidt I, Torrez M, Schwabe C, Benavente L, Seocharan I, Jituboh D, Nseng G, Sharp B: Factors influencing the effectiveness of malaria control in Bioko Island, equatorial Guinea. Am J Trop Med Hyg 2007, 76:1027-1032.

5. Cook J, Kleinschmidt I, Schwabe C, Nseng G, Bousema T, Corran PH, Riley EM, Drakeley CJ: Serological markers suggest heterogeneity of effectiveness of malaria control interventions on Bioko Island, equatorial Guinea. PLoS One 2011, 6:e25137.

6. Sharp BL, Ridl FC, Govender D, Kuklinski J, Kleinschmidt I: Malaria vector control by indoor residual insecticide spraying on the tropical island of Bioko. Equatorial Guinea. Malaria J 2007, 6:52.

7. Shaukat AM, Breman JG, McKenzie FE: Using the entomological inoculation rate to assess the impact of vector control on malaria parasite transmission and elimination. Malaria J 2010, 9:122.

8. Reddy MR, Overgaard HJ, Abaga S, Reddy VP, Caccone A, Kiszewski AE, Slotman MA: Outdoor host seeking behaviour of Anopheles gambiae mosquitoes following initiation of malaria vector control on Bioko Island. Equatorial Guinea. Malaria J 2011, 10:184.

9. Overgaard HJ, Saebo S, Reddy MR, Reddy VP, Abaga S, Matias A, Slotman MA: Light traps fail to estimate reliable malaria mosquito biting rates on Bioko Island. Equatorial Guinea. Malaria J 2012, 11:56.

10. Pappa V, Reddy M, Overgaard HJ, Abaga S, Caccone A: Estimation of the Human Blood Index in malaria mosquito vectors in Equatorial Guinea after indoor antivector interventions. Am J Trop Med Hyg 2011, 84:298-301.

11. Deitz KC, Athrey G, Reddy MR, Overgaard HJ, Matias A, Jawara M, Della Torre A, Petrarca V, Pinto J, Kiszewski AE, et al: Genetic isolation within the malaria mosquito Anopheles melas. Mol Ecol 2012, 21:4498-513.

12. Cohnstaedt LW, Gillen JI, Munstermann LE: Light-emitting diode technology improves insect trapping. J Am Mosa Control Assoc 2008, 24:331-334.

13. Scott JA, Brogdon WG, Collins FH: Identification of single specimens of the Anopheles gambiae complex by the polymerase chain reaction. Am J Trop Med Hyg 1993, 49:520-529.

14. Fanello C, Santolamazza F, Della Torre A: Simultaneous identification of species and molecular forms of the Anopheles gambiae complex by PCR-RFLP. Med Vet Entomol 2002, 16:461-464.

15. Morassin B, Fabre R, Berry A, Magnaval JF: One year's experience with the polymerase chain reaction as a routine method for the diagnosis of imported malaria. Am J Trop Med Hyg 2002, 66:503-508.

16. Bass C, Nikou D, Donnelly MJ, Williamson MS, Ranson H, Ball A, Vontas J, Field LM: Detection of knockdown resistance $(\mathrm{kdr})$ mutations in
Anopheles gambiae: a comparison of two new high-throughput assays with existing methods. Malaria J 2007, 6:111.

17. Bass C, Nikou D, Vontas J, Donnelly MJ, Williamson MS, Field LM: The Vector Population Monitoring Tool (VPMT): high-throughput DNA-based diagnostics for the monitoring of mosquito vector populations. Malar Res Treat 2010, 2010:190434.

18. Molina R, Benito A, Blanca F, Roche J, Otunga BJA: The Anophelines of Equatorial Guinea, Ethology and susceptibility studies. Res Rev Parasitol 1996, 56:105-110.

19. Hay SI, Rogers DJ, Toomer JF, Snow RW: Annual Plasmodium falciparum entomological inoculation rates (EIR) across Africa: literature survey, Internet access and review. Trans R Soc Trop Med Hyg 2000, 94:113-127.

20. Gething PW, Patil AP, Smith DL, Guerra CA, Elyazar IR, Johnston GL, Tatem AJ, Hay SI: A new world malaria map: Plasmodium falciparum endemicity in 2010. Malaria J 2011, 10:378.

21. Hay SI, Guerra CA, Tatem AJ, Atkinson PM, Snow RW: Urbanization, malaria transmission and disease burden in Africa. Nat Rev Microbiol 2005, 3:81-90

22. Bockarie MJ, Service MW, Barnish G, Toure YT: Vectorial capacity and entomological inoculation rates of Anopheles gambiae in a high rainfall forested area of southern Sierra Leone. Trop Med Parasitol 1995, 46:164-171.

23. Cano J, Berzosa PJ, Roche J, Rubio JM, Moyano E, Guerra-Neira A, Brochero H, Mico M, Edu M, Benito A: Malaria vectors in the Bioko Island (Equatorial Guinea): estimation of vector dynamics and transmission intensities. J Med Entomol 2004, 41:158-161.

24. Van Bortel W, Delacollette C, Barutwanayo M, Coosemans M: Deltamethrinimpregnated bednets as an operational tool for malaria control in a hyper-endemic region of Burundi: impact on vector population and malaria morbidity. Trop Med Int Health 1996, 1:824-835.

25. Njam Nloga A, Robert V, Toto JC, Carnevale P: Anopheles moucheti, vecteur principal du paludisme au sud Cameroun. Bull Liaison Doc OCEAC 1993, 26:63-67.

26. Gadiaga L, Machault V, Pages F, Gaye A, Jarjaval F, Godefroy L, Cisse B, Lacaux JP, Sokhna C, Trape JF, Rogier C: Conditions of malaria transmission in Dakar from 2007 to 2010. Malaria J 2011, 10:312.

27. Bradley J, Matias A, Schwabe C, Vargas D, Monti F, Nseng G, Kleinschmidt I: Increased risks of malaria due to limited residual life of insecticide and outdoor biting versus protection by combined use of nets and indoor residual spraying on Bioko Island. Equatorial Guinea. Malaria J 2012, 11:242.

28. Reimer LJ, Tripet F, Slotman M, Spielman A, Fondjo E, Lanzaro GC: An unusual distribution of the kdr gene among populations of Anopheles gambiae on the island of Bioko, Equatorial Guinea. Insect Mol Biol 2005, 14:683-688.

29. Weill M, Chandre F, Brengues C, Manguin S, Akogbeto M, Pasteur N, Guillet P, Raymond M: The kdr mutation occurs in the Mopti form of Anopheles gambiae s.s. through introgression. Insect Mol Biol 2000, 9:451-455.

30. Simard F, Ayala D, Kamdem GC, Pombi M, Etouna J, Ose K, Fotsing JM Fontenille D, Besansky NJ, Costantini C: Ecological niche partitioning between Anopheles gambiae molecular forms in Cameroon: the ecological side of speciation. BMC Ecol 2009, 9:17.

31. Ridl FC, Bass C, Torrez M, Govender D, Ramdeen V, Yellot L, Edu AE, Schwabe C, Mohloai P, Maharaj R, Kleinschmidt I: A pre-intervention study of malaria vector abundance in Rio Muni, Equatorial Guinea: their role in malaria transmission and the incidence of insecticide resistance alleles. Malar J 2008, 7:194.

32. Molina R, Benito A, Roche J, Blanca F, Amela C, Sanchez A, Alvar J: Baseline entomological data for a pilot malaria control program in Equatorial Guinea. J Med Entomol 1993, 30:622-624.

33. WHO: Global Plan for Insecticide Resistance Management in malaria vectors (GPIRM). Geneva: World Health Organization, WHO/HTM/GMP/2012.5; 2012. http://www.who.int/malaria/vector_control/ivm/gpirm/en/index.html

34. Athrey G, Hodges TK, Reddy M, Overgaard HJ, Arnez A, Atue M, Abaga S, Caccone A, Slotman MA: The effective population size of malaria mosquitoes: large impact of vector control. PLoS Genet 2012, in press.

35. Russell TL, Govella NJ, Azizi S, Drakeley CJ, Kachur SP, Killeen GF: Increased proportions of outdoor feeding among residual malaria vector populations following increased use of insecticide-treated nets in rural Tanzania. Malaria J 2011, 10:80.

doi:10.1186/1756-3305-5-253

Cite this article as: Overgaard et al:: Malaria transmission after five years of vector control on Bioko Island, Equatorial Guinea. Parasites \& Vectors $20125: 253$ 